\title{
Diffractive trifocal lens implantation with or without excimer laser enhancement: is a touch-up procedure a negative predictor for refractive and subjective outcome?
}

\author{
Anne-Karen von Beckerath ${ }^{1} \cdot$ Toam Katz $^{1,2,3} \cdot$ Anna Harfst $^{1} \cdot$ Vasyl Druchkiv $^{1,2,3}$ • Andreas Frings ${ }^{4,5,6}$
}

Received: 9 October 2019 /Revised: 6 February 2020 / Accepted: 12 February 2020 / Published online: 19 February 2020

(C) The Author(s) 2020

\begin{abstract}
Purpose To investigate the refractive results of a LASIK enhancement and its impact on treatment safety, efficacy, predictability and patient reported outcome in eyes after clear lens extraction and diffractive trifocal lens implantation.

Methods A retrospective cohort multicentre study of Care Vision Refractive Centres in Germany compared two groups of patients. Group 1 consisted of eyes that had non-toric MIOL surgery only, whereas group 2 had a consecutive laser enhancement after 3 months follow-up. Refractive and subjective results of the two groups were compared. Patient reported outcome measurements were assessed by using a 30-item questionnaire with four subscales.

(Spectacle Dependence, Eye Comfort, Freedom and Looking/Feeling Well). Refractive results were reported following standard reporting in refractive surgery.

Results 139 eyes of 79 patients were included in which either MIOL surgery or MIOL surgery plus LASIK enhancement had been performed between January and December 2017. UDVA reached $0.1 \operatorname{logMAR}(0.8 ; 20 / 25)$ in $94 \%$ in group 2 and $85 \%$ in group 1. Compared to preoperative CDVA no change in Snellen lines of CDVA was shown in $89 \%$ in group 1 and in $93 \%$ in group 2. Spectacle dependence $(P=0.41)$, eye comfort $(P=0.15)$, freedom $(P=0.48)$ and looking/feeling well $(P=0.45)$ showed no statistically significant difference between both the groups.

Conclusions In patients with residual ametropia after MIOL implantation, LASIK provides a reliable, safe and efficient way to achieve the desired refractive outcome and patient satisfaction. We recommend performing Laser enhancement at 3 months after MIOL implantation (Bioptics) in trifocal MIOL patients that benefit from improvement of residual ametropia.
\end{abstract}

Keywords Laser enhancement · LASIK · MIOL-implantation · Touch-up procedure

\section{Introduction}

Shared first authorship Anne-Karen von Beckerath and Toam Katz

Andreas Frings

andi.frings@gmail.com

1 Medical University Hamburg, Martinistr. 52, 20251 Hamburg, Germany

2 Care Vision Hamburg, Martinistr. 52, 20251 Hamburg, Germany

3 Department of Ophthalmology, University Hamburg, Martinistr. 52, 20251 Hamburg, Germany

4 Department of Ophthalmology, Heinrich-Heine-University, Moorenstr. 5, 40225 Düsseldorf, Germany

5 UCL Institute of Ophthalmology, 11-43 Bath St, London EC1V 9EL, UK

6 Care Vision Nuremberg, Zeltnerstr. 1-3, 90443 Nuremberg, Germany
Multifocal intraocular lenses (MIOL) are reliable treatment options. However, to work well, MIOLs must fulfil some conditions. Among others, a crucial point which reduces the success of any MIOL is residual postoperative ametropia, mostly as refractive cylinder left after MIOL surgery. In these cases, the MIOL simply cannot fulfil its full working range thereby resulting in loss of lines of distance and near uncorrected visual acuity (UDVA, UNVA) as well as patient dissatisfaction. To meet the expectations of patients and surgeons in cases of postoperative ametropia, a laser enhancement surgery - also called Bioptics - is a popular surgical option to treat the residual ametropia - usually the refractive cylinder - left in the optical system. In our experience, Laser in situ keratomileusis (LASIK) is the method of choice compared to photorefractive keratectomy (PRK) as it goes along with faster recovery of visual acuity and usually patient 
satisfaction. This study was initiated to investigate refractive and subjective results of eyes with a laser enhancement procedure after MIOL surgery and its impact on treatment safety, efficacy and predictability.

\section{Material and methods}

This retrospective multicentre study aimed at analysing refractive and subjective results following implantation of a non-toric, aspheric refractive-diffractive hydrophobic trifocal intraocular lens (MIOL; Fine Vision Pod F, PhysIOL, Belgium) in eyes with mild pre-operative topographic astigmatism. In spite of a preoperative refractive cylinder the surgeon may indicate a nontoric MIOL and expect a reduction of corneal astigmatism by positioning of the corneal incisions. Two age- and gendermatched study groups were retrospectively defined: Group 1 consisted of eyes that had non-toric MIOL surgery only, whereas group 2 had a consecutive laser enhancement $($ Bioptics $=$ nontoric MIOL surgery + consecutive LASIK) after 3 months follow-up (FU). The main indication for a touch-up procedure was a symptomatic difference between CDVA and UDVA, mainly due to postoperative refractive cylinder. Laser enhancements were free of charge and based on manifest refraction, and target refraction for MIOL surgery and laser enhancement was emmetropia in all cases. MIOL surgery was offered to young non-presbyopic myopes with healthy posterior segments (in case they were not fit for laser vision correction or ICL surgery), presbyopes and young nonpresbyopic high hyperopes. The latter were not suitable for keratorefractive surgery or phakic lens implantation.

According to our standard operation procedure ("Care Vision Consensus") MIOL surgery was offered to patients that fulfilled the following criteria:

- Distance corrected visual acuity of 0.63 decimal (0.2logMAR; 20/32) or better.

- Binocular near corrected near visual acuity of 0.63 decimal $(0.2 \log$ MAR; 20/32) or better (Jaeger chart "No. 4" or better).

- In case of presbyopia binocular uncorrected near visual acuity of 0.63 decimal $(0.2 \log$ MAR; 20/32) or worse (Jaeger chart "No. 4" or worse).

- Photopic pupil diameter $2.00 \mathrm{~mm}$ and more.

- Axial length less than $26.00 \mathrm{~mm}$ with healthy posterior segments.

- Endothelial cell counts of at least 2000 cells $/ \mathrm{mm}^{2}$.

Following the above-mentioned indications, we divided this analysis into myopic and hyperopic patients ("young nonpresbyopic myopes versus presbyopic hyperopes"). Since preoperative UNVA of the hyperopes is much worse than of myopes we expected a higher improvement of UNVA post MIOL in hyperopic eyes compared to pre-operative myopic eyes which may affect their satisfaction.

All data were retrieved from the Hamburg Refractive Database (University Hospital Hamburg-Eppendorf and Care Vision Refractive Centres in Germany). All patients had a FU of at least 3 months after the MIOL surgery and, in cases with Bioptics, another 3 months after the enhancement. For analysis, the results of the MIOL surgery only cases (Group 1) were compared to the results obtained by Bioptics cases (Group 2). All data was measured 3 months after the final treatment. No eye had a posterior capsule opacification or YAG capsulotomy had already been performed at the time of the clinical measurements. All patients gave written informed consent for data analysis during the recruiting process for surgery. The retrospective study adhered to the tenets of the Declaration of Helsinki.

\section{Surgical treatment}

The MIOL surgeries and laser enhancement procedures followed a standard protocol of indications as well as pre-, intra- and postoperative management written and implemented by one of the first authors of this study (T.K.). The power of the trifocal MIOL was calculated using a laser interferometer (IOL Master 500, Zeiss, Germany) using the Haigis formula aiming at emmetropia. MIOL surgery cases were performed by three surgeons in three Care Vision Clinics in Germany and followed a standard approach phacoemulsification with complication-free implantation of a posterior chamber lens. Paracenteses (1$1.5 \mathrm{~mm}$ ) were incised at the limbus perpendicularly to the phaco incision, in most cases at 3 and 9 o'clock position. On the steep meridian a $2.4 \mathrm{~mm}$ wide incision was made. We did not perform Femtosecond-assisted surgery. A trifocal MIOL (Pod F, Physiol) was inserted into and centred in the capsular bag using an injector and a $1.8 \mathrm{~mm}$ wide cartridge. All incisions were self-sealing, sutures were not required.

Group 2 were treated with Bioptics as follows: We used a microkeratome (Moria SBK 90, France) to create a flap with nasal hinge and an Allegretto Excimer Laser platform (EQ. 400 Wavelight $\mathrm{GmbH})$ with eye tracking $(250 \mathrm{~Hz})$ in all cases, supported by a Neurotrack system (Wavelight $\mathrm{GmbH}$ ) to minimize cyclotorsion.

Criteria for a touch-up procedure were:

- Patient dissatisfaction with postoperative uncorrected (distance) visual acuity and thus patient request for an improvement after demonstrating changes of near and distance visual acuity that would be reached by a touch-up procedure.

- Lack of ocular pathologies that would diminish visual acuity independent of ametropia (for example posterior capsule opacification, macular edema, superficial punctate keratitis).

- Stable subjective refraction defined as a maximum difference of 0.50 D SE between two consecutive follow-up examinations (4 weeks versus 12 weeks after MIOL surgery). 
- A maximum difference of $0.25 \mathrm{D}$ of refractive cylinder and/or sphere between two consecutive follow-up examinations (4 weeks versus 12 weeks after MIOL surgery); in eyes with refractive cylinder of $0.75 \mathrm{D}$ or higher less than $20^{\circ}$ change of subjective cylinder axis.

- Regular corneal topography not contraindicating corneal laser surgery according to the previously mentioned Standard Operating Procedure (SOP / Consensus).

- All patients were examined on day 1, day 7 and 1 and 3 months after MIOL surgery and on day 1, day 7 and 3 months after LASIK touch-up.

\section{Patient reported outcome measurements}

Patient reported outcome measurements were assessed by using a 30-item questionnaire with four subscales (Spectacle Dependence, Eye Comfort, Freedom and Looking/Feeling Well). The questionnaire was part of a field study as described previously (please refer to: https://clinicaltrials.gov/ct2/show/ NCT03655743). All items were translated into German and tested within cognitive interviews before applied in the field study. Cognitive interviews were conducted to optimize face validity (comprehensibility) of items and response options. A trained interviewer (Anna Harfst) conducted all of the cognitive interviews. Participants were asked to describe in their own words what each item was asking and in some cases to compare different ways of asking the same question. As a result of these interviews, items could be further simplified, some words could be deleted, some items could be reworded, and some parts of the question stems could be added to response options for clarity.

\section{Statistical analysis}

Refractive results were reported following conventions published previously. To analyse predictability of the treatment, linear regression was applied. A $P$ value of 0.05 or less was defined as statistically significant.

\section{Results}

This retrospective multicentre analysis included data of 139 eyes of 79 patients in which either MIOL surgery or MIOL surgery plus LASIK enhancement had been performed between January and December 2017 (mean age 29.8 \pm 10.04 , range 21 to 62 years). Table 1 summarises pre- and postoperative spherical equivalent (SE) for both the study groups, subdivided in pre-operatively hyperopic and myopic eyes.

Postoperatively, uncorrected distance visual acuity (UDVA) reached $0.1 \log$ MAR $(0.8 ; 20 / 25)$ in $94 \%$ of eyes with Bioptics and $85 \%$ of eyes with MIOL only (Fig. 1). In eyes with Bioptics, 79\% had a postoperative UDVA of at least preoperative corrected distance visual acuity (CDVA). UDVA equalled CDVA in $66 \%$ and was better in $3 \%$ of eyes with MIOL only (Fig. 2). There was no change in Snellen lines of CDVA in $89 \%$ and $93 \%$ in MIOL and Bioptics eyes, respectively (Fig. 3). Predictability of SE change was high in both the study groups (Fig. 4) with $88 \%$ (Bioptics) versus $83 \%$ (MIOL) within 0.50 Dioptre of the attempted SE (Fig. 5).

\section{Subjective outcome}

Looking at the subscales Spectacle Dependence $(P=0.41)$, Eye Comfort $(P=0.15)$, Freedom $(P=0.48)$ and Looking/ Feeling Well $(P=0.45)$, there were no statistically significant differences between MIOL-only and Bioptics eyes. Moreover, overall satisfaction $(P=0.23)$ did also show no statistically significant difference (Fig. 6).

\section{Discussion}

In this retrospective study we expected that eyes that did not need a Bioptic (Group 1) will have better objective results than eyes in group 2 before they got their Bioptic. The relative lower objective and subjective visual performance of group 2 is the reason why they were entitled for a touch-up LASIK. This seemingly clear division into "satisfied" vs "still not satisfied" MIOL patients

Table 1 (a) Cases per group, (b) Pre- and postoperative spherical equivalent for both the study groups

\begin{tabular}{|c|c|c|c|c|c|c|c|c|}
\hline A) & Bioptics & MIOL & & & & & & \\
\hline Total & 68 & 71 & & & & & & \\
\hline Myopes & 13 & 11 & & & & & & \\
\hline Hyperopes & 55 & 60 & & & & & & \\
\hline \multirow[t]{3}{*}{ B) } & \multicolumn{4}{|c|}{ Prior to surgery } & \multicolumn{4}{|c|}{ At 3 months follow-up } \\
\hline & \multicolumn{2}{|l|}{ Bioptics } & \multicolumn{2}{|l|}{ MIOL } & \multicolumn{2}{|c|}{ Bioptics } & \multicolumn{2}{|l|}{ MIOL } \\
\hline & Mean & $\begin{array}{l}\text { Standard Deviation } \\
\text { (Range) }\end{array}$ & Mean & $\begin{array}{l}\text { Standard Deviation } \\
\text { (Range) }\end{array}$ & Mean & $\begin{array}{l}\text { Standard Deviation } \\
\text { (Range) }\end{array}$ & Mean & $\begin{array}{l}\text { Standard Deviation } \\
\text { (Range) }\end{array}$ \\
\hline Myopes & -6.19 & $3.64(-15.25$ to -1.50$)$ & $-3,82$ & $2.57(-7.75$ to -0.25$)$ & 0.03 & $0.37(-0.50$ to 0.75$)$ & 0.2 & $0.27(-0.25$ to 0.625$)$ \\
\hline Hyperopes & 2.56 & $1.87(0.25$ to 8.50$)$ & 1.95 & $1.28(0.125$ to 5125$)$ & 0.1 & $0.35(-0.50$ to 1.50$)$ & 0.03 & $0.4(-0.75$ to 0.875$)$ \\
\hline
\end{tabular}



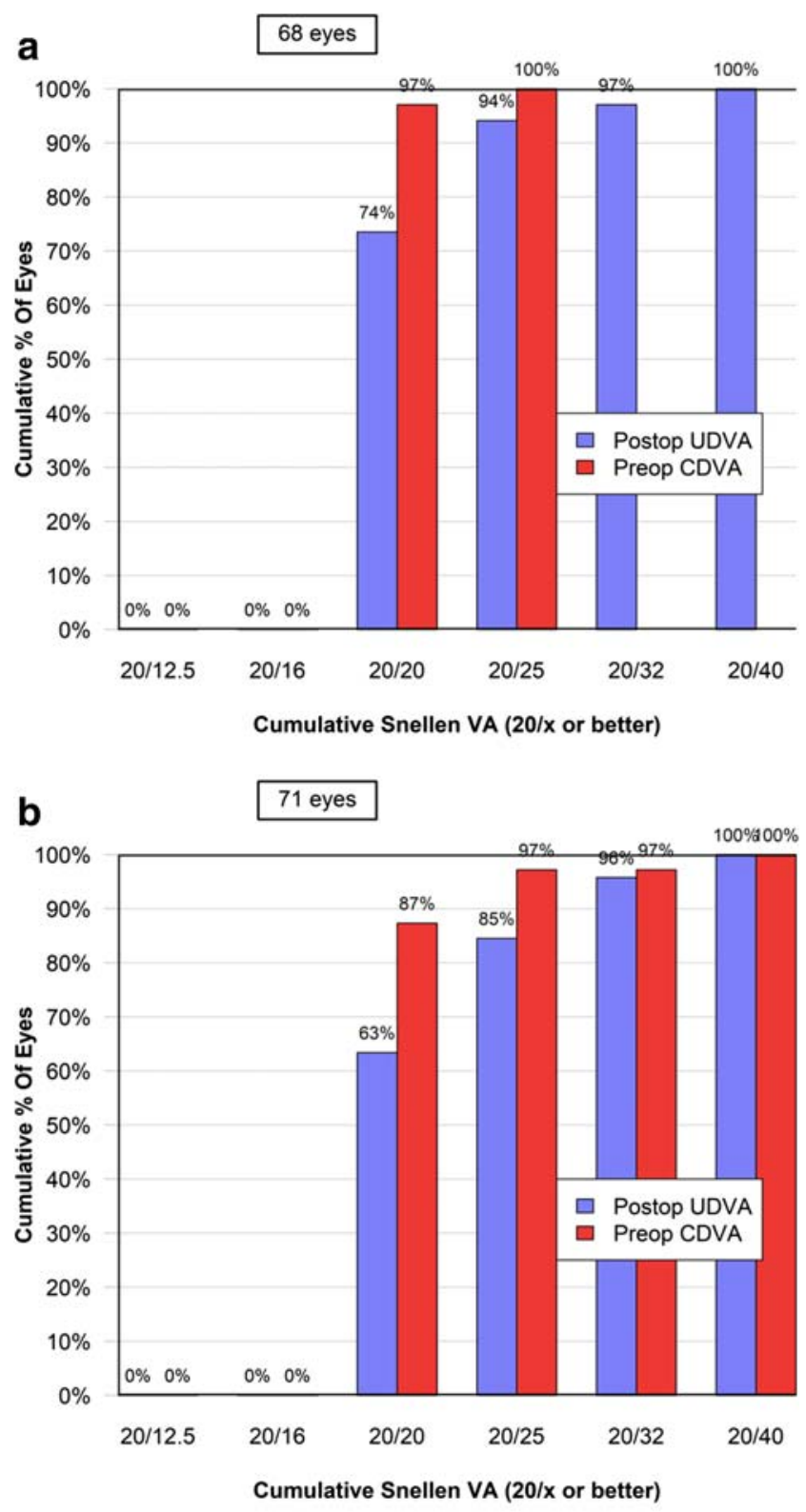

Fig. 1 Preoperative corrected distance visual acuity (CDVA) and postoperative uncorrected distance visual acuity (UDVA) after Bioptics (a) and MIOL surgery (b)

raises clinically relevant questions: Can a Bioptic regain the good results of an emmetropic eye after MIOL surgery? Or does an excimer laser surgery in a certain age group cause more discomfort than satisfaction? And maybe the dissatisfaction after MIOL implantation reflects the character and personality of the patient rather than his or her visual acuity? In our experience after MIOL implantation most eyes do have a minimal measurable ametropia but very good visual performance and satisfaction. However, which threshold of ametropia should be eligible to offer an additional surgery on the cornea?

A refractive cylinder as low as 0.75 Dioptre can significantly limit visual acuity [1]. In eyes after MIOL implantation and an
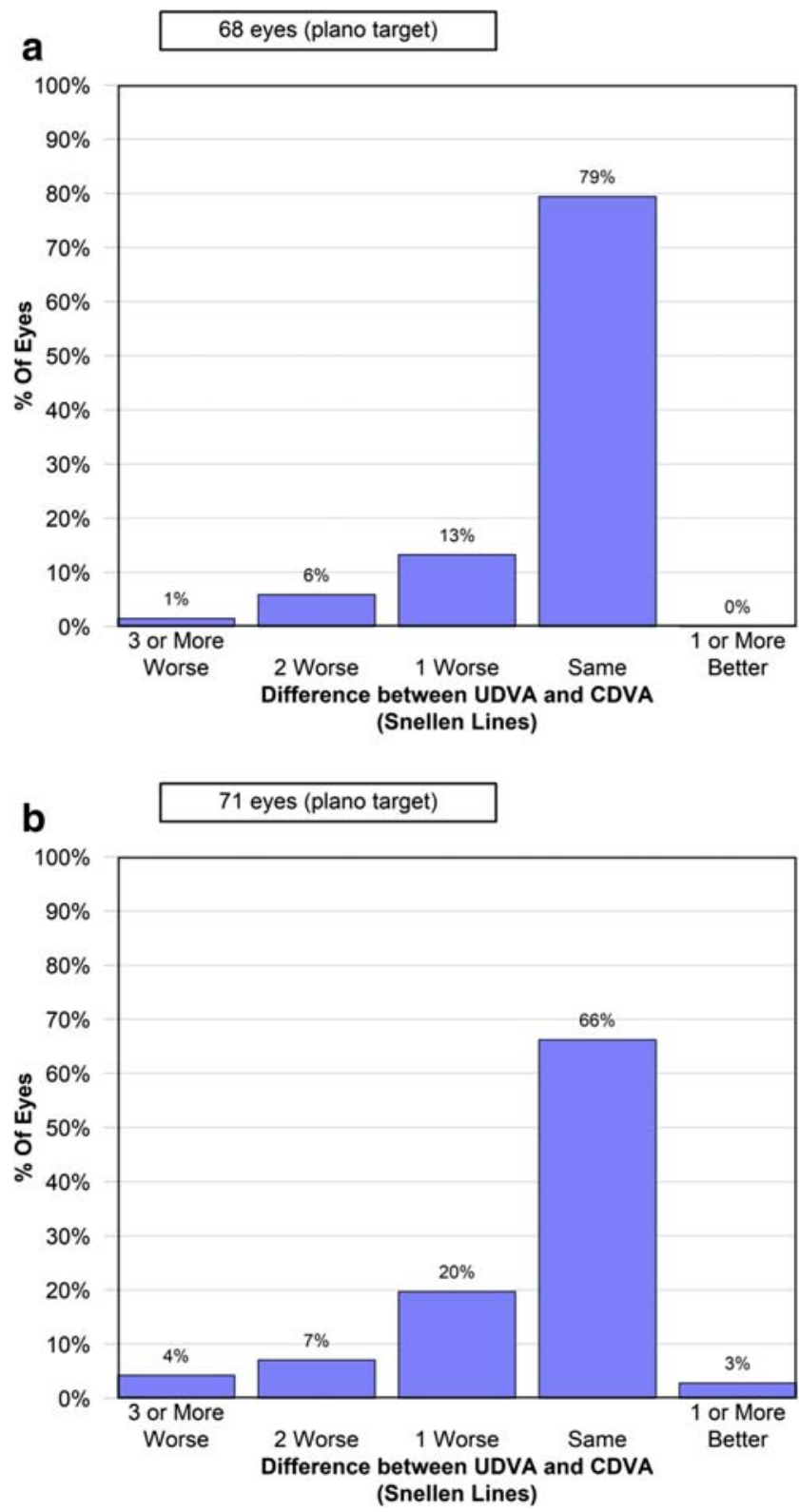

Fig. 2 Difference between preoperative corrected distance visual acuity (CDVA) and postoperative uncorrected distance visual acuity (UDVA) after Bioptics (a) and MIOL surgery (b)

uncorrected refractive cylinder, objective and subjective results are usually below expectations [2-7]. In a previous study, the authors showed that almost 1 in 3 eyes were limited by a postsurgical refractive cylinder as low as $0.75 \mathrm{D}$ or higher [6]. In another study by de Vries et al. a refractive cylinder was present in more than 2 of 3 eyes after non-toric MIOL implantation. Another large scaled study on surgical results of 17.000 individuals with cataract surgery concluded that almost 1 in 2 eyes planned for emmetropia did not reach a postsurgical SE of 0.50 Dioptre or less [8].

Independent of the reasons of a postsurgical refractive cylinder - either unwanted SIA or non-corrected preoperative topographic astigmatism - sometimes combined with residual 

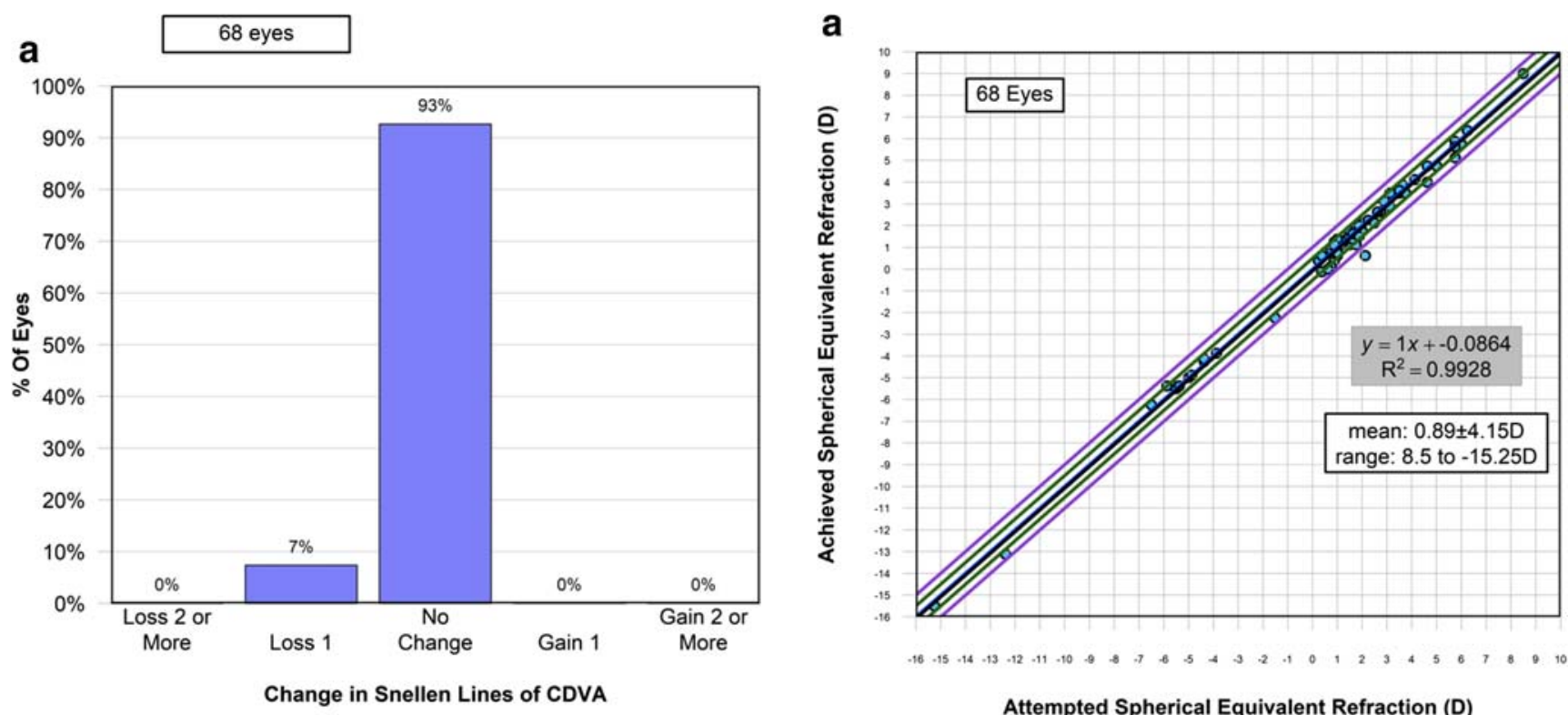

Attempted Spherical Equivalent Refraction (D)

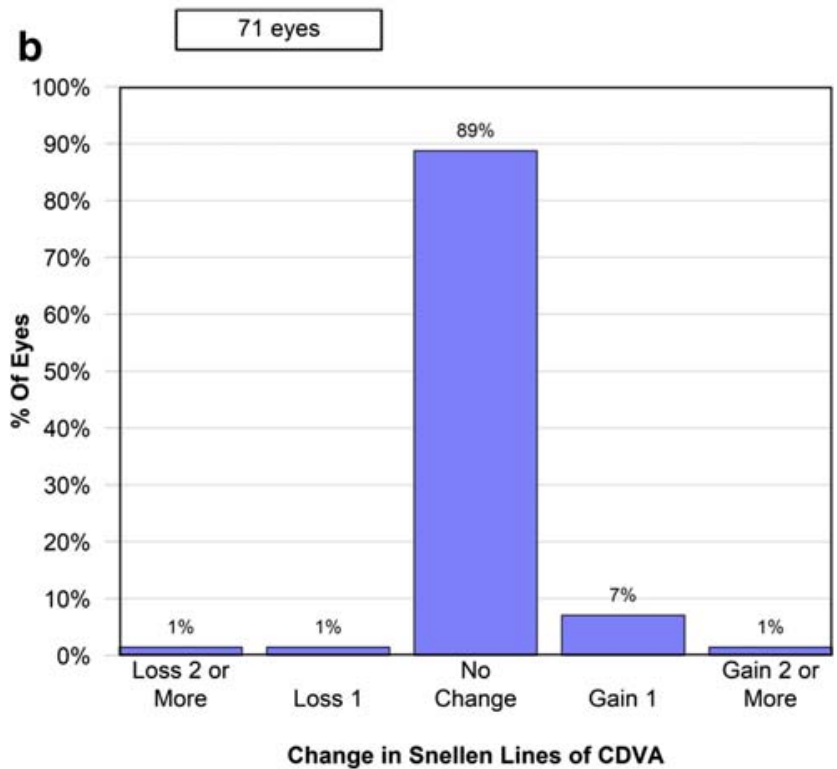

b

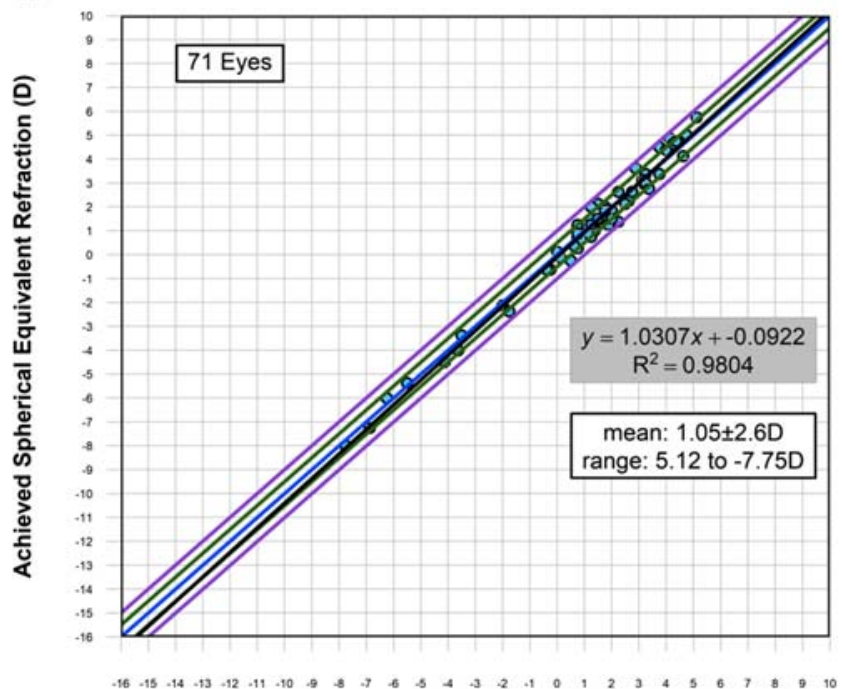

Fig. 3 Changes in Snellen lines of pre- versus postoperative corrected distance visual acuity (CDVA) after Bioptics (a) and MIOL surgery (b)

spherical error, patients with a MIOL demand UDVA of 20/20 or better. The function of the diffractive implant itself depends on postoperative emmetropia to deliver its expected optical performance. In case of post MIOL ametropia, Bioptics preferably LASIK enhancement -is a simpler method than any secondary intraocular surgery to reach the initial goal.

With our study, we aimed to compare objective and subjective results of patients that needed a touch-up surgery to reach a better UDVA (Bioptics group 2) with patients that had already reached final UDVA without a compromising refractive cylinder (MIOL-only group 1).

Our results show that:

Laser enhancements raise the visual performance to the same level as of trifocal MIOL eyes that did not need a touch-up.

\section{Attempted Spherical Equivalent Refraction (D) \\ Fig. 4 Predictability of spherical equivalent change (attempted versus achieved refraction) after Bioptics (a) and MIOL surgery (b)}

Laser enhancements raise the subjective satisfaction to the same level as of trifocal MIOL eyes that did not need a touch-up.

Our findings go in line with previous data from Venter et al. (2013) [9] and Muftuoglu et al. (2009) [10]. Both these studies report on high predictability, efficacy and safety of laser enhancement in MIOL eyes to treat the refractive cylinder.

This retrospective study focuses on non-toric MIOL implantation in eyes with low cylinder. Doubtlessly, there is high evidence that using toric lenses in eyes with significant topographic astigmatism results in high predictability and patient satisfaction [10-12]. However, some patient with a toric MIOL still have a refractive cylinder left after the surgery, most likely due to SIA or misalignment of the toric MIOL. 

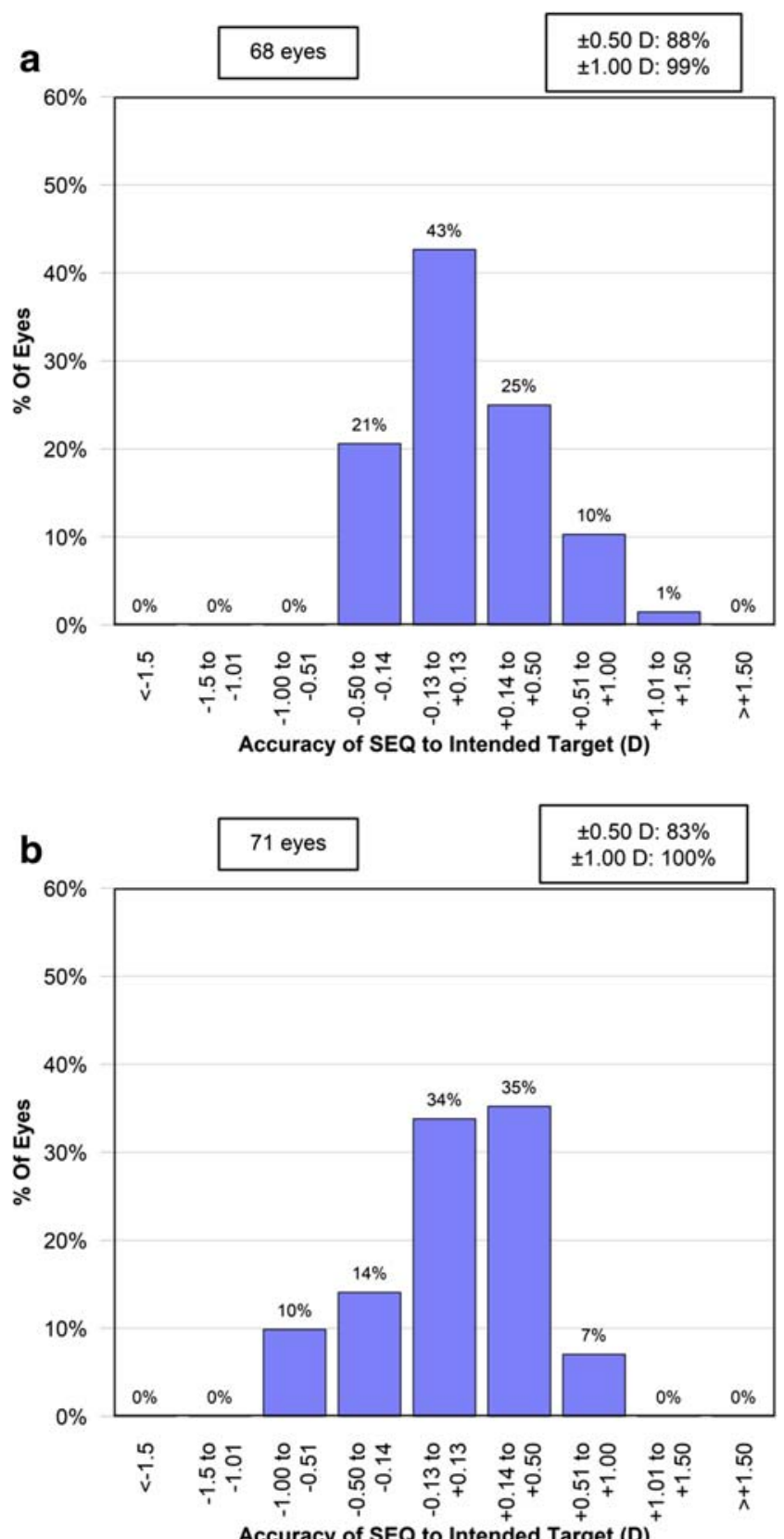

Fig. 5 Absolute difference between postoperative spherical equivalent and the intended target (emmetropia) after Bioptics (a) and MIOL surgery (b)

Although the current study does not analyse results of laser enhancement in toric IOL eyes, its conclusions may be implicated for this patient group as well.

There are arguments in favour of using non-toric lenses with a prior planned laser touch-up in eyes that might otherwise have been indicated for a toric lens. Schallhorn et al. [13] present an analysis of almost 800 eyes with MIOL implantation and showed that less than $50 \%$ reached emmetropia in terms of $\pm 0.50 \mathrm{D}$ SE. Excimer laser surgery was performed and lead to refractive and subjective improvement of treatment results in 9 of 10 eyes. In their study, the number of patients that reported to be unsatisfied

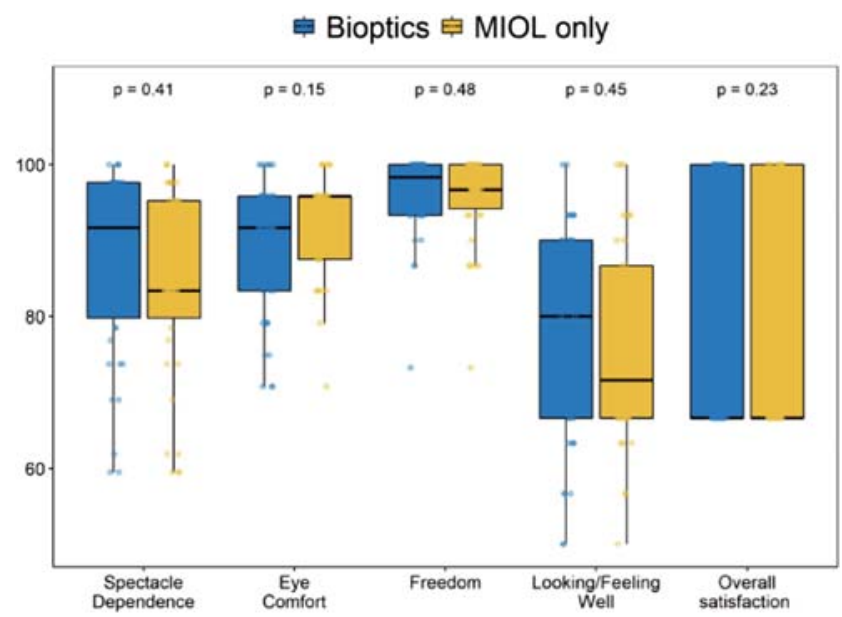

Fig. 6 Results of patient reported outcome measurements between Bioptics and MIOL only eyes assessed by using 30 items of 4 subscales (Spectacle Dependence, Eye Comfort, Freedom and Looking/Feeling Well). There were no statistically significant differences in the aforementioned domains between the two study groups

or very unsatisfied with the treatment outcome decreased statistically significantly after the touch-up from 17 to $9 \%(P<0.001)$.

In our study, fifteen eyes of the MIOL-only group had a postoperative refractive cylinder of 1.00 Dioptre and more at the 3-month FU. However, in these eyes the mean SE was $0.12 \pm 0.33$ Dioptres, ranging between -0.625 and 0.625 . Interestingly, these patients did not show a statistically significant difference in subjective outcome as binocular visual acuity reached UDVA of 0.8 and more. None of these eyes lost lines in CDVA (when tested monocularly), and all patients had an UDVA (binocular) better than the driving standard. There were no statistically significant differences between patient reported outcome measurements when looking at the subscales Spectacle Dependence $(P=0.41)$, Eye Comfort $(P=0.15)$, Freedom $(P=0.48)$ and Looking/Feeling Well $(P=0.45)$. Moreover, overall satisfaction $(P=0.23)$ did also show no statistically significant difference which means that patients with a Bioptic reported on the same satisfaction levels. With other words, the enhancement procedure did not diminish objective outcome and thus, it did not affect patient satisfaction with the overall result of the treatment. These findings go in line with previous studies $[5,13-15]$. There are three limitations to our retrospective non-randomised study. First, the questionnaire used here has not been fully validated yet. Secondly, we did not measure subjective satisfaction and its increase after MIOL implantation before the laser enhancement in the Bioptics group to analyse its effect. Third, we did not match individuals between study groups as per preoperative refraction (although they were matched age- and gender-wise). In this set-up of elective refractive lens exchange and MIOL implantation a prospective randomised study is not implacable. The advantages of this study are the standardised SOP, pre- intra and postoperative indications, devices and methods used by a relatively large number of human eyes within a short time. 
To conclude, our study results show that:

1. Laser enhancement at 3 months after trifocal MIOL implantation (Bioptics) delivers the same refractive results compared to eyes in which the "second shot" was not necessary.

2. Laser enhancement at 3 months after trifocal MIOL implantation (Bioptics) is safe, efficient and predictable.

3. MIOL patients with Laser enhancement report the same outcome as MIOL-only cases when asked about their subjective satisfaction with the "second shot", being done free-of-charge.

We recommend performing laser enhancement at 3 months after MIOL implantation (Bioptics) in trifocal MIOL patients that benefit from improvement of residual ametropia.

Author contribution The present work was performed in fulfilment of the requirements for obtaining the degree "Dr. Med." (Anne-Karen von Beckerath).

Funding Information Open Access funding provided by Projekt DEAL. No funding was received for this research. However, Dr. Frings was supported by a grant from the Ernst-und-Berta-Grimmke Stiftung.

\section{Compliance with ethical standards}

Conflict of interest No Conflicts of Interest.

All authors certify that they have no affiliations with or involvement in any organisation or entity with any financial interest (such as honoraria; educational grants; participation in speakers' bureaus; membership, employment, consultancies, stock ownership, or other equity interest; and expert testimony or patent-licencing arrangements), or non-financial interest (such as personal or professional relationships, affiliations, knowledge or beliefs) in the subject matter or materials discussed in this manuscript

Ethical approval All procedures performed in studies involving human participants were in accordance with the ethical standards of the institutional and/or national research committee and with the 1964 Helsinki declaration and its later amendments or comparable ethical standards.

Informed consent Informed consent was obtained from all individual participants included in the study.

Open Access This article is licensed under a Creative Commons Attribution 4.0 International License, which permits use, sharing, adaptation, distribution and reproduction in any medium or format, as long as you give appropriate credit to the original author(s) and the source, provide a link to the Creative Commons licence, and indicate if changes were made. The images or other third party material in this article are included in the article's Creative Commons licence, unless indicated otherwise in a credit line to the material. If material is not included in the article's Creative Commons licence and your intended use is not permitted by statutory regulation or exceeds the permitted use, you will need to obtain permission directly from the copyright holder. To view a copy of this licence, visit http://creativecommons.org/licenses/by/4.0/.

\section{References}

1. Wolffsohn JS, Bhogal G, Shah S (2014) Astigmatism and vision: should all astigmatism always be corrected? Br J Ophthalmol 98:2-3

2. Pepose JS, Qazi MA, Davies J, Doane JF, Loden JC, Sivalingham V, Mahmoud AM (2007) Visual performance of patients with bilateral vs combination Crystalens, ReZoom, and ReSTOR intraocular lens implants. Am J Ophthalmol 144:347-357

3. Vingolo EM, Grenga P, Iacobelli L, Grenga R (2007) Visual acuity and contrast sensitivity: AcrySof ReSTOR apodized diffractive versus AcrySof SA60AT monofocal intraocular lenses. J Cataract Refract Surg 33:1244-1247

4. Zeng M, Liu Y, Liu X, Yuan Z, Luo L, Xia Y, Zeng Y (2007) Aberration and contrast sensitivity comparison of aspherical and monofocal and multifocal intraocular lens eyes. Clin Exp Ophthalmol 35:355-360

5. Alfonso JF, Fernández-Vega L, Montés-Micó R, Valcárcel B (2008) Femtosecond laser for residual refractive error correction after refractive lens exchange with multifocal intraocular lens implantation. Am J Ophthalmol 146:244-250

6. Woodward MA, Randleman JB, Stulting RD (2009) Dissatisfaction after multifocal intraocular lens implantation. J Cataract Refract Surg 35:992-997

7. Zheleznyak L, Kim MJ, MacRae S, Yoon G (2012) Impact of corneal aberrations on throughfocus image quality of presbyopiacorrecting intraocular lenses using an adaptive optics bench system. J Cataract Refract Surg 38:1724-1733

8. Behndig A, Montan P, Stenevi U, Kugelberg M, Zetterström C, Lundström M (2012) Aiming for emmetropia after cataract surgery: Swedish National Cataract Register study. J Cataract Refract Surg 38:1181-1186

9. Venter JA, Pelouskova M, Collins BM, Schallhorn SC, Hannan SJ (2013) Visual outcomes and patient satisfaction in 9366 eyes using a refractive segmented multifocal intraocular lens. J Cataract Refract Surg 39:1477-1484

10. Muftuoglu O, Prasher P, Chu C, Mootha VV, Verity SM, Cavanagh HD, Bowman RW, McCulley JP (2009) Laser in situ keratomileusis for residual refractive errors after apodized diffractive multifocal intraocular lens implantation. J Cataract Refract Surg 35:1063-1071

11. Ernest P, Potvin R (2011) Effects of preoperative corneal astigmatism orientation on results with a low-cylinder-power toric intraocular lens. J Cataract Refract Surg 37:727-732

12. Shodai R, Negishi K, Arai H, Toda I, Torii H, Tsubota K (2017) Comparative analysis of the visual and refractive outcomes of a refractive segmented multifocal intraocular lens with and without toricity: 1-year results. Jpn J Ophthalmol 61:142-149

13. Schallhorn SC, Venter JA, Teenan D, Schallhorn JM, Hettinger KA, Hannan SJ, Pelouskova M (2016) Outcomes of excimer laser enhancements in pseudophakic patients with multifocal intraocular lens. Clin Ophthalmol 10:765-767

14. Alió JL, Elkady B, Ortiz D, Bernabeu G (2008) Clinical outcomes and intraocular optical quality of a diffractive multifocal intraocular lens with asymmetrical light distribution. J Cataract Refract Surg 34:942-948

15. Alió JL, Plaza-Puche AB, Piñero DP, Amparo F, Jiménez R, Rodríguez-Prats JL, Javaloy J, Pongo V (2011) Optical analysis, reading performance, and quality-of-life evaluation after implantation of a diffractive multifocal intraocular lens. J Cataract Refract Surg 37:27-37

Publisher's note Springer Nature remains neutral with regard to jurisdictional claims in published maps and institutional affiliations. 